\section{'One-stop' cataract surgery: the Bristol Eye Hospital experience 1997-1999}

In recent years more and more cataract surgery has been done under local anaesthesia as a day case. Overall $86 \%$ of cataract operations in this country are done under local anaesthetic. ${ }^{2}$ There is considerable regional variation in the day case rate, which despite being $70 \%$ overall can be as low as $10 \%$ in some units and as high as $100 \%$ in others. ${ }^{2}$ In many units patients will still attend the hospital on three separate occasions for an outpatient visit, pre-operative assessment and then surgery. A recent publication by the NHS Executive, 'Action on Cataracts', has encouraged 'streamlining the pathway of diagnosis and treatment' with same-day diagnosis and preoperative assessment. ${ }^{3}$

A 'one-stop' cataract service operated in our unit on a trial basis between February 1997 and August 1999 and we have assessed both patient satisfaction with the service and its viability as a prospect for providing a more efficient cataract surgery service.

\section{Methods}

One hundred and ninety patients referred with a view to cataract surgery were selected from their referral letter to attend 24 'one-stop' clinics between February 1997 and August 1999. Patients were selected from their GOS18 and GP: letter (having been referred for a routine outpatient appointment) on the basis of living a long distance from the ophthalmic unit and/or reasonable general health as indicated by the GP referral letter. Patients were sent a letter warning them that surgery would be undertaken on the same day if appropriate, and that they should be prepared for this. There was initial assessment in the morning with biometry and consultation with an ophthalmology SHO before being seen by the consultant who performed the surgery that afternoon. Each clinic invited 9 new patients with the intention to operate on approximately 8 per list.

Forty patients undergoing 'one-stop' surgery and 40 control patients (three separate visits) were surveyed with a postal questionnaire 
A) Was this your first cataract operation? $\mathrm{Y} \quad \mathrm{N}$

B) Was your surgery done under local anaesthetic? Y N

C) Were you a day-case patient (did you go home the same day)?

$\mathrm{Y} \quad \mathrm{N}$

D) Were you satisfied with the explanation given of the operation?

$\begin{array}{lll}\text { Very satisfied } & \text { Satisfied } & \text { Indifferent } \\ \text { Dissatisfied } & \text { Very dissatisfied } & \end{array}$

E) Were you satisfied with the time you were given to decide whether you wanted a cataract operation?

$\begin{array}{lll}\text { Very satisfied } & \text { Satisfied } & \text { Indifferent } \\ \text { Dissatisfied } & \text { Very dissatisfied } & \end{array}$

F) Overall what was your opinion of the service provided at the Bristol Eye Hospital?

$\begin{array}{lll}\text { Very good } & \text { Good } & \text { Moderate } \\ \text { Fairly poor } & \text { Poor } & \end{array}$

Fig. 1. Cataract surgery questionnaire.

(Fig. 1) to determine satisfaction with the service provided and with the time allowed to decide whether or not to have surgery.

\section{Results}

One hundred and fifty-six of $190(82.1 \%)$ patients invited to 'one-stop' clinics underwent surgery that day. Table 1 illustrates the reasons for the 34 patients not having surgery as planned. The number of operations per list averaged 6.5 (range 4-8).

Questionnaires were returned by 35 (88\%) 'one-stop' patients and 37 (93\%) control group patients. Results are summarised in Table 2.

Overall satisfaction with the service was not statistically different between the groups, with 33 (94\%) of 'one-stop' and 35 (95\%) of control patients judging the service 'very good'. The remainder of patients in both groups found the service 'good'.

Twenty-eight 'one-stop' patients were 'very satisfied' and $7(20 \%)$ 'satisfied' with the time allowed to make a decision about surgery, compared with 21 (57\%) 'very satisfied' and 16 (43\%) 'satisfied' in the control group ( $p=0.06$, Fisher's exact test). None of the 'one-stop' (or

Table 1. Reasons for patients not having surgery as a 'one-stop' procedure $(\mathrm{n}=34)$

\begin{tabular}{lr}
\hline Reason & No. \\
\hline Inappropriate referral (i.e. insignificant cataract) & $10(29 \%)$ \\
Patient declined surgery (i.e. significant cataract, & $5(15 \%)$ \\
patient not keen after discussion of risks/benefits) & \\
Surgery done later under general anaesthesia & $4(12 \%)$ \\
(unsuitable for local anaesthesia) & \\
Did not attend & $3 \quad(9 \%)$ \\
Patient not prepared for same-day surgery & $3(9 \%)$ \\
Other ocular pathology (ARMD) & $2 \quad(6 \%)$ \\
Hypertensive & $2 \quad(3 \%)$ \\
High INR (on warfarin) & $1 \quad(3 \%)$ \\
Miscellaneous (including 1 deceased) & $4(12 \%)$ \\
\hline
\end{tabular}

ARMD, age-related macular degeneration; INR, International Normalised Ratio.
Table 2. Patient satisfaction questionnaire results

\begin{tabular}{lccccc}
\hline & \multicolumn{5}{c}{ Level of satisfaction } \\
\cline { 2 - 6 } & 1 & 2 & 3 & 4 & 5 \\
\hline One-stop $(n=35)$ & 26 & 9 & 0 & 0 & 0 \\
Explanation of surgery & 28 & 7 & 0 & 0 & 0 \\
Time to make decision & 33 & 2 & 0 & 0 & 0 \\
Overall service & & & & & \\
Control $(n=37)$ & 28 & 7 & 1 & 1 & 0 \\
Explanation of surgery & 21 & 6 & 0 & 0 & 0 \\
Time to make decision & 35 & 2 & 0 & 0 & 0 \\
Overall service &
\end{tabular}

${ }^{a}$ Level of satisfaction: 1 = very good/very satisfied. 2 = good/ satisfied, 3 = indifferent $/$ moderate, 4 = poor $/$ disatisfied, 5 = very poor/very dissatisfied.

control) patients was dissatisfied with the time allowed for making the decision whether or not to proceed with surgery.

\section{Discussion}

'One-stop' cataract surgery has obvious benefits for patients in reducing attendances at hospital from three to one while the patients have a date for their surgery right from the outset. From the results of our questionnaire there is a high level of patient satisfaction with this service.

One of the initial concerns raised about the serivice was that patients may not have enough time in which to make a balanced decision about surgery and that some may feel pressurised into going ahead. It was suggested that patients should have a 'cooling off' period to consider whether to undergo surgery after the initial consultation. The results of the questionnaire do not suggest that patients experienced this difficulty. However, none of our 'one-stop' or control patients had significant complications so we were unable to compare the responses of a subgroup of patients who had problems. Both the General Medical Council and Medical Protection Society were consulted by J.P.D. with regard to the issue of how much time should be allowed to give informed consent. Neither body considered this issue should preclude 'one-stop' surgery. Patients were not sent information about cataract surgery procedures or associated risks prior to their attendance at hospital.

From our experience with 'one-stop' there are several other points that warrant discussion. The unpredictable nature of the clinic content meant that although on average $82 \%$ of patients had surgery on the day, this could be as low as $50 \%$, leading to inefficient use of theatre time. The problem of inefficiency was overcome to an extent later in the programme by adding a few non'one-stop' patients to the clinic who were warned that there was a chance of surgery that day and to come prepared for this possibility. These non-'one-stop' patients could fill in gaps where fewer than 8 'one-stop' patients required surgery. 
Success of a 'one-stop' system requires an experienced surgeon (and anaesthetist) to deal with unpredictable problems inherent in such unscreened patients, such as previous trauma or dense cataracts.

'One-stop' surgery offers a streamlined service to some patients but not to those who are listed from general clinics, e.g. those under review for co-morbidity such as glaucoma or those whose cataract was incidental to the referral letter.

The advantages of 'one-stop' cataract surgery are clear. The service acts to directly link the rate of outpatient review with the rate of surgery, thereby eliminating the second waiting list (time from listing to time of surgery). Only a single wait exists, i.e. referral to surgery. The reduction of total hospital visits frees up resources and appears to be popular with patients.

On balance, although the authors feel that 'one-stop' cataract surgery has been shown to be a viable prospect and has obvious patient-orientated benefits, the potential short-falls (in particular wasted theatre space) mean that this system may have little overall advantage over sameday diagnosis/pre-assessment clinics with a later date for surgery. However, this balance may shift in favour of 'one-stop' surgery for certain patient groups such as those who live a considerable distance from the hospital or who require support (e.g. ambulance transport, accompanying relatives or support workers) for each hospital visit.

\section{References}

1. Jay JL, Devlin MC. The increasing frequency of surgery for cataract. Eye 1990;4:127-31.

2. Desai P, Reidy A, Minassian DC. Profile of patients presenting for cataract surgery in the UK: national data collection. Br J Ophthalmol 1999;83:893-6.

3. Action on Cataracts. NHS Executive, Department of Health, Feb 2000. 